\title{
The Psilotreta Banks, 1899 of the Dabie Mountains, east central China, with descriptions of two new species (Insecta: Trichoptera: Odontoceridae)
}

\author{
Shuang QIU ${ }^{1} \&$ Yun-jun YAN ${ }^{2, *}$ \\ ${ }^{1,2}$ Huazhong University of Science and Technology, College of Life Science and Technology, \\ Lab of energy Biotechnology and Ecology, Luo-yu Road 1037, Wuhan, Hubei, China. \\ ${ }^{2, *}$ Corresponding author: yanyunjun@hust.edu.cn \\ ${ }^{1}$ Email: shirleyqiu@aliyun.com \\ ${ }^{1}$ urn:1sid:zoobank.org:author:1BD1D49E-143C-4657-AD92-5C0213BC20A8 \\ ${ }^{2}$ urn:1sid:zoobank.org:author:14203221-5D33-48B2-BB18-1E2CAC2B0432
}

\begin{abstract}
The authors collected caddisflies in the Dabie Mountains in 2014 and 2015. Three species of Psilotreta Banks, 1899 were found: Psilotreta daidalos Malicky, 2000, P. furcata sp. nov., and $P$. brevispinosa sp. nov. The species were collected by light sheet traps or hand nets near streams in mountainous forests. All the species are described and illustrated, and the species groups to which they belong are discussed. Some variation within $P$. daidalos is described and the species is newly recorded from the Anhui and Hubei Provinces.
\end{abstract}

Keywords. Taxonomy, Dabie Mountains, oriental biogeographic region, caddisfly, Odontoceridae.

Qiu S. \& Yan Y. 2020. The Psilotreta Banks, 1899 of the Dabie Mountains, east central China, with descriptions of two new species (Insecta: Trichoptera: Odontoceridae). European Journal of Taxonomy 601: 1-11. https://doi.org/10.5852/ejt.2020.601

\section{Introduction}

Psilotreta Banks, 1899 is a genus of the family Odontoceridae Wallengren, 1891 and currently contains 68 species worldwide (Morse 2018). Among them, 55 species are distributed in the Oriental region; others may be found in the East Palearctic or Nearctic regions. By the end of 2015, 32 species of Psilotreta had been recorded in China (Yang et al. 2016).

Oláh \& Johanson (2010) found three diagnostic species groups in this genus: the Psilotreta japonica species group, the $P$. trimeresuri species group and the $P$. frontalis species group. The species groups are defined by the position of the harpagones, the number and size of apical spines on the harpagones and the number of phallic parameres in the phallus. 
Members of both the Psilotreta japonica and P. trimeresuri species groups are found in China. The differences between these two species groups are: (1) in the P. japonica group the harpagones are located at the apices of the coxopodites, in the $P$. trimeresuri group the harpagones are located mesally; and (2) in the P. japonica group there is one pair of spines in the phallic apparatus while in the P. trimeresuri group there are two pairs of spines. However, many species in China possess a combination of characters from these two species groups. For example, Psilotreta spinata Yuan \& Yang, 2008, and P. expers Yuan \& Yang, 2008 both have harpagones located mesally on the coxopodites, but with only one pair of spines in the phallus. Moreover, Psilotreta bicruris Yuan \& Yang, 2011, and P. paulula Yuan \& Yang, 2011 have harpagones located at the apices of the coxopodites, but with two pairs of spines in the phallus.

Yuan et al. (2008) also studied Psilotreta and found the length ratio of the maxillary palp segments and wing veins could be characters useful in delineating different species groups. They also recognized several species groups that were different from Oláh \& Johanson's classification (Yuan \& Yang 2008, 2010, 2011). Afterwards, Yuan \& Yang (2013) published data on new species with a key to Psilotreta species groups of China and adjacent regions, they also divided part of this genus into five species groups: the Psilotreta chinensis species group, the $P$. apiculata species group, the P. monacantha species group, the $P$. kwantungensis species group and the $P$. jaroschi species group. The Chinese species mentioned above can be classified well using Yuan \& Yang's key. Therefore, the discussion of species groups in this article mainly follows Yuan \& Yang (2013).

In this article, we will introduce two new species from the Dabie Mountains, east central China. Descriptions and illustrations are provided; the species groups for the new species are also discussed.

\section{Material and methods}

Samples were taken in 2014 and 2015; detailed site data are included in the material examined section. Most adult specimens were collected by light sheet traps at night, although some were collected by hand nets in daytime alongside streams. All specimens are preserved in 95\% ethanol. Specimens were examined under a stereo microscope. Abdomens of males were dissected and placed in $10 \% \mathrm{KOH}$ overnight to remove the non-chitin structures; cleaned abdomens and male genitalia were put in glycerin for observation. An eyepiece with grids was used for illustration on paper with grids. The sketches were scanned and digital illustrations were completed in the software Inkscape (ver. 0.48.4.0). Holotypes are deposited in Nanjing Agriculture University, College of Plant Protection, Specimens Room. Paratypes are deposited in Huazhong University of Science and Technology, College of Life Science and Technology, Institute of Bioenergy and Ecology.

\section{Institutional abbreviations}

$\mathrm{NAU}=$ Nanjing Agriculture University

HUST $=$ Huazhong University of Science and Technology

Terminology of male genitalia mainly follows Nielsen (1957), except the terminology of segment X and phallus which follow Parker \& Wiggins (1987). Terminology of setae warts on the head follows Oláh \& Johanson (2007). 


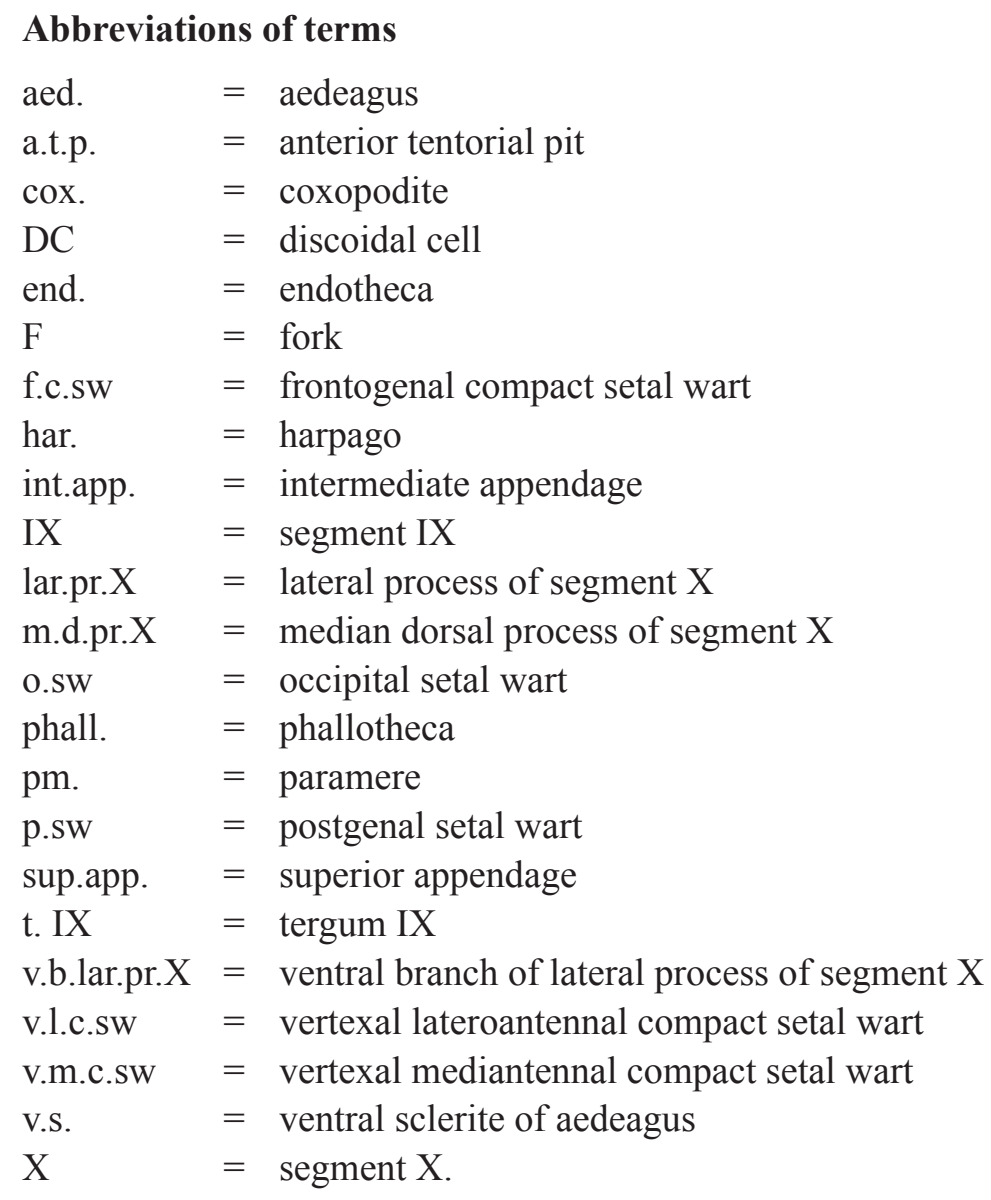

\section{Results}

Class Insecta Linnaeus, 1758

Order Trichoptera Kirby, 1813

Suborder Integripalpia Martynov, 1924

Infraorder Brevitentoria Weaver, 1984

Family Odontoceridae Wallengren, 1891

Subfamily Odontocerinae Wallengren, 1891

Genus Psilotreta Banks, 1899

As the original description of Psilotreta daidalos Malicky, 2000 is in German, we provide a full description of this species to facilitate future taxonomic studies.

Psilotreta daidalos Malicky, 2000

Fig. 1

\section{Diagnosis}

The male genitalia of this species resemble those of P. trispinosa Schmid, 1965, but can be distinguished by the following characters: (1) intermediate appendages are single (intermediate appendages of P. trispinosa are trifid); (2) each lateral process of segment $\mathrm{X}$ acute apically (in P. trispinosa, lateral process of segment $\mathrm{X}$ round apically); (3) parameres are short, approximately half as long as aedeagus (parameres of $P$. trispinosa about as long as aedeagus). 


\section{Material examined}

CHINA - Anhui Province 1 o ; Yuexi County, Yao-luo-ping Nature Preserve, close to the \#28 Red Army's historic sites; 3059'10.66" N, 1165'53.26" E; 1141 m a.s.1.; 9 May 2015; Qiu Shuang and Liu

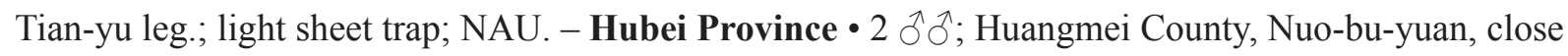
to Lao-zu Temple; $30^{\circ} 13^{\prime} 48.87^{\prime \prime}$ N, 11549'53.60" E; 919 m a.s.1.; 24 Jun. 2015; Qiu Shuang and Liu Tian-yu 1eg.; light sheet trap; HUST.

\section{Description}

\section{Male}

HEAD. In anterior view, frons with groove located between antennae; frontogenal compact setal warts oblanceolate, adjacent to compound eyes; anterior tentorial pits located close to clypeus, with clypeogenal vertical grooves located ventrally; row of short scratches located dorsally of anterior tentorial pits (Fig. 1A). In dorsal view, vertexal mediantennal compact setal warts semicircular; vertexal lateroantennal compact setal warts subtriangular, posterior ends proximal to occipital setal warts; occipital setal warts large, touched with each other in center of head, slightly concave at anterior margin; postgenal setal warts small, slender (Fig. 1B). Maxillary palp segment length ratio 1:1.1:1.8:1.7:2.5 (Fig. 1C).

WINGS. Forewings each 7.4-8.0 mm $(\mathrm{n}=2)$, yellow, discoidal cell (DC) present, fork I is approximately one third longer than fork II; $\mathrm{R}_{4+5}$ not fused with $\mathrm{R}_{3}, \mathrm{Cu}_{2}$ absent; row of setae located in close proximity to posterior margin of each forewing. Hind wings each present with Sc close to R1 mid-span, DC present (Fig. 1D).

MaLe GEnitalia. Tergum IX broad in lateral view (Fig. 1E), triangular in dorsal view (Fig. 1F); sternum IX broad in lateral and ventral views (Fig. 1E, 1G). Median dorsal process of segment X oblanceolate (Fig. 1F); lateral process highly modified (Fig. 1I), with sharp process anteriorly, sub-triangular process and thin long lateral branch posteriorly in lateral view. Intermediate appendage present, short and strongly hooked (Fig. 1I). Superior appendage digitate in dorsal and lateral views (Fig. 1E-1F). Coxopodites with bases wider than apices in lateral view (Fig. 1E), rectangular in ventral view (Fig. 1G); harpagones each coniform, with numerous small round spines spread at apex (Fig. 1G). Phallotheca strongly sclerotized, slightly curved ventrad, truncated at apex in lateral view (Fig. 1H); parameres present, basal half humped dorsally in lateral view, apex acute, in ventral view curved mesad at bases and curved laterad at apex (Fig. 1J); aedeagus slightly sclerotized at base, apex membranous, with small hump in lateral view and pair of lobes in ventral view (Fig. 1H, 1K); ventral sclerite of aedeagus curved at base, and expanded at apex in lateral view (Fig. 1H), pandurate in ventral view (Fig. 1K).

\section{Comments}

Compared with Malicky's (2000) descriptions and illustrations, the specimens in Henan Province have the intermediate appendages more strongly curved than those in Anhui and Hubei Provinces. The ventral sclerite of the aedeagus of specimens from Henan Province is slender, not pandurate as we described. The shapes of other structures are similar.

\section{Distribution}

The type locality of this species is in Henan Province (Malicky 2000), now we report it from Anhui and Hubei Provinces. 

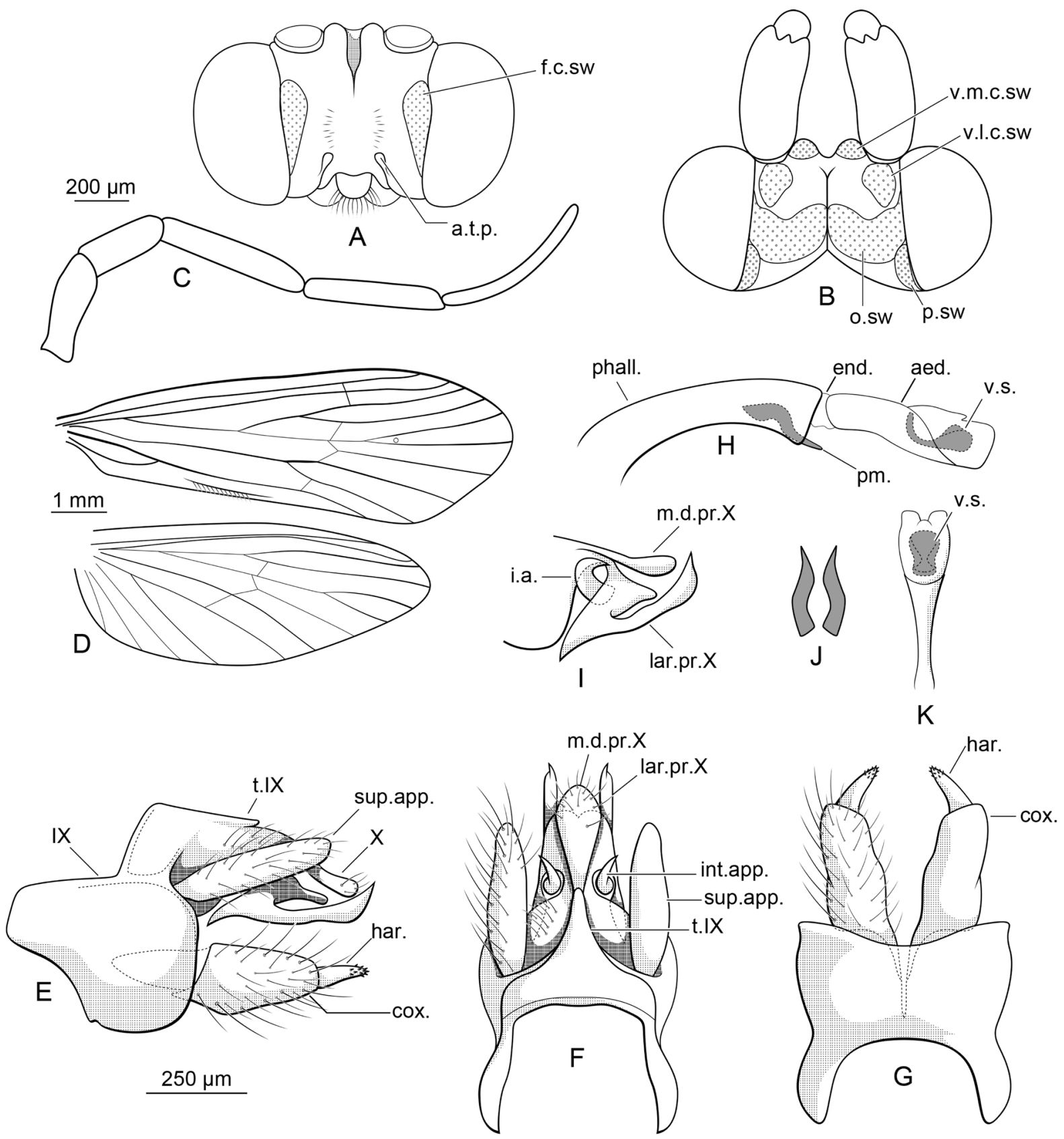

Fig. 1. Psilotreta daidalos Malicky 2000. A. Head, anterior view. B. Head, dorsal view. C. Maxillary palp. D. Wing veins. E. Male genitalia, left lateral view. F. Male genitalia, dorsal view. G. Male genitalia, ventral view. H. Phallus, left lateral view. I. Segment X, left lateral view. J. Parameres, ventral view. K. Aedeagus, ventral view. Scale bars: $\mathrm{A}-\mathrm{C}=200 \mu \mathrm{m} ; \mathrm{D}=1 \mathrm{~mm} ; \mathrm{E}-\mathrm{K}=250 \mu \mathrm{m}$. 


\section{Psilotreta furcata sp. nov. urn:1sid:zoobank.org:act:445EFA06-FF9A-4775-BAC8-61F93D4C1482}

Fig. 2

\section{Diagnosis}

The male genitalia of this new species resemble those of $P$. quinlani Kimmins, 1964, but can be distinguished by the following characters: (1) the median dorsal process of segment $\mathrm{X}$ is more than $3 \times$ as long as wide in dorsal view (short in P. quinlani, about as long as wide in dorsal view); (2) ventral branch of lateral process of segment $\mathrm{X}$ is simple and slender, directly pointed posteriorly in lateral view (in P. quinlani, ventral branch of lateral process of segment $\mathrm{X}$ is more complicated, directed ventrally and reduced to a digitate projection curving posteriorly in lateral view); and (3) superior appendages each round at apex in lateral view (superior appendages of $P$. quinlani each triangular at apex in lateral view).

\section{Etymology}

The specific name is derived from the Latin 'furcata', or English 'furcate', referring to the forked median dorsal process of segment $\mathrm{X}$.

\section{Material examined}

\section{Holotype}

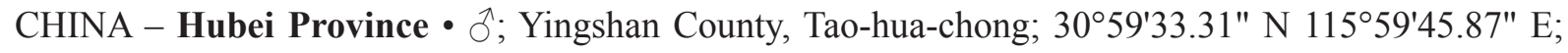
469 m a.s.1.; 6 May 2015; Qiu Shuang and Liu Tian-yu 1eg.; light sheet trap; NAU.

\section{Paratype}

CHINA - Hubei Province • 1 o ; same collection data as for holotype; HUST.

\section{Description}

\section{Male}

HEAD. In anterior view, frons located with pit between antennae, with short dark line extended below pit. Frontogenal compact setal warts slender, in close proximity to compound eyes laterally, and next to pair of wide grooves mesally (Fig. 2A). In dorsal view, with dark median dorsal line dissipating before reaching posterior margin, vertexal mediantennal compact setal warts proximal to each other, and smaller than vertexal lateroantennal compact setal warts. Occipital setal warts round, postgenal setal warts digitate. Antennae present with tube-like structure within (Fig. 2B). Maxillary palp segments length ratio 1:0.9:1.7:1.5:1.8 (Fig. 2C).

WiNGs. Forewings each 8.9-9.2 mm $(\mathrm{n}=2)$, yellow, round at apex; DC present, fork I about $1 / 3$ longer than fork II, $\mathrm{R}_{4+5}$ not fused with $\mathrm{R}_{3}, \mathrm{Cu}_{2}$ absent; row of setae located close to posterior margin of each forewing. Hind wings with R1 straight, Sc and R2 slightly curved at crossvein Sc-r and r separated, DC absent (Fig. 2D).

Male genitalia. Tergum IX triangular in dorsal view (Fig. 2F), narrow in lateral view (Fig. 2E). Sternum IX wide in lateral and ventral views (Fig. 2E). Main body of segment $\mathrm{X}$ hexagonal in dorsal view (Fig. 2F); median dorsal process of segment X narrow in lateral view (Fig. 2E), V-shaped in dorsal view (Fig. 2F), about $3 \times$ as long as wide; ventral branch of lateral process of segment $\mathrm{X}$ narrow, slightly curved in lateral view (Fig. 2I), curved mesad at apex in dorsal view (Fig. 2F). Intermediate appendage small, with two sharp tips dorsally (Fig. 2I). Superior appendages digitate in lateral view (Fig. 2E), narrower basally than apically in dorsal view (Fig. 2F). Coxopodites thick, slightly narrowed at bases in lateral view (Fig. 2E), curved laterad in ventral view (Fig. $2 \mathrm{G}$ ); harpagones about $1 / 3$ as long as 


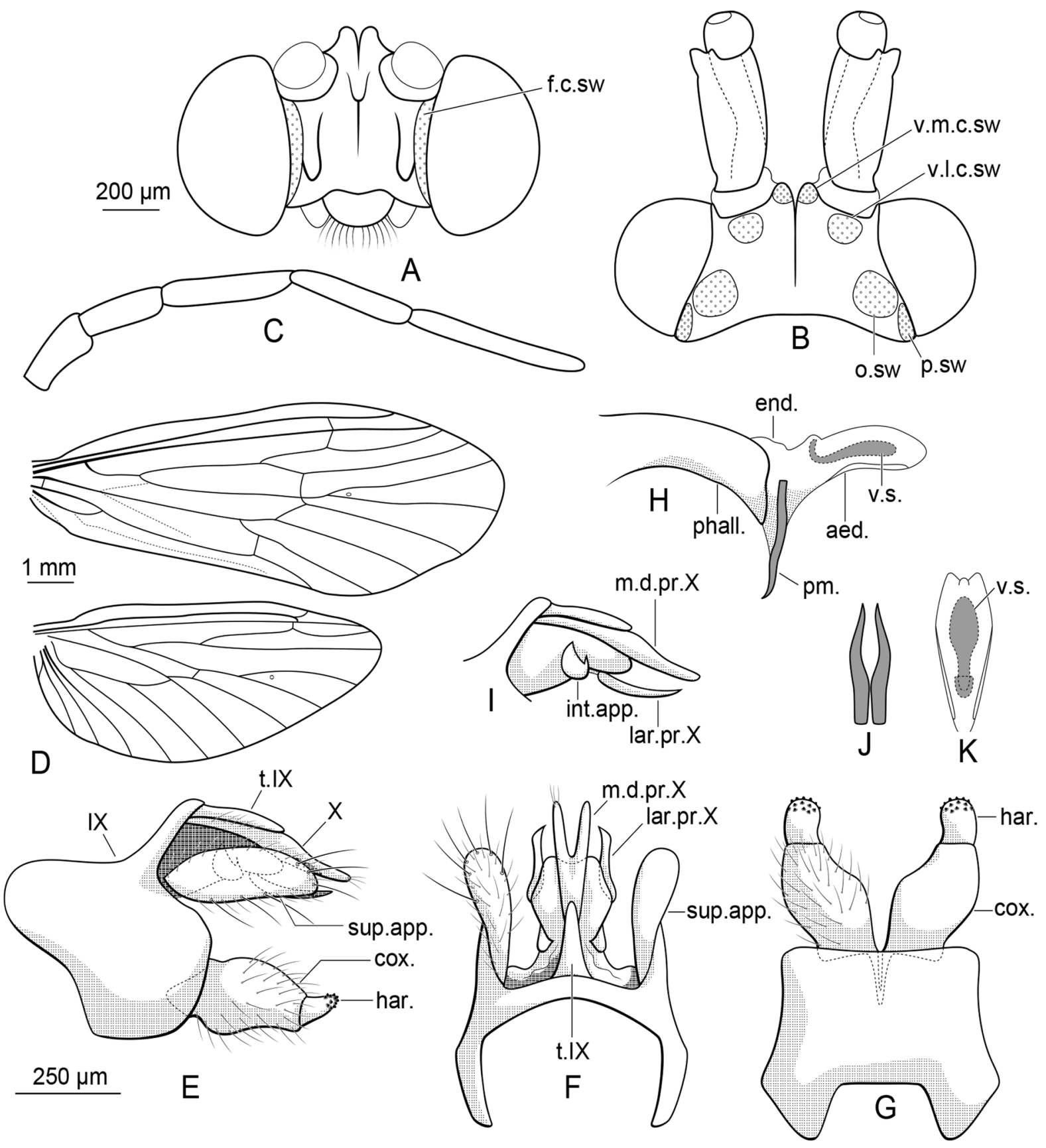

Fig. 2. Psilotreta furcata sp.nov. A. Head, anterior view. B. Head, dorsal view. C. Maxillary palp. D. Wing veins. E. Male genitalia, left lateral view. F. Male genitalia, dorsal view. G. Male genitalia, ventral view. H. Phallus, left lateral view. I. Segment X, left lateral view. J. Parameres, posterior view. K. Aedeagus, dorsal view. Scale bars: $\mathrm{A}-\mathrm{C}=200 \mu \mathrm{m} ; \mathrm{D}=1 \mathrm{~mm} ; \mathrm{E}-\mathrm{K}=250 \mu \mathrm{m}$. 
coxopodites, apices round, with short round spines (Fig. 2G). Phallotheca slightly sclerotized, with apex truncate in lateral view (Fig. 2H); parameres long, slightly curved mesally at apices in posterior view (Fig. 2J); aedeagus slightly sclerotized ventrally; ventral sclerite of aedeagus narrow, curved at about 90 degrees in lateral view (Fig. 2H) and spatulate in dorsal view (Fig. 2K).

\section{Distribution}

The type location is in the Hubei Province, but the distributions is otherwise unknown.

Psilotreta brevispinosa sp. nov.

urn:1sid:zoobank.org:act:438E2AA5-6111-45E0-AF2B-410A67810EA9

Fig. 3

\section{Diagnosis}

The male genitalia of this new species stand apart from those of other species of Psilotreta species by the huge superior appendages, the absence of an intermediate appendage and the short, anteriorly curved lateral process of segment $\mathrm{X}$.

\section{Etymology}

The specific name is derived from the Latin 'brevi-' and 'spinosa', meaning 'short' and 'spines', referring to the pair of short spines on the lateral process of segment X.

\section{Material examined}

\section{Holotype}

CHINA - Henan Province - ${ }^{\lambda}$; Xinyang County, Tian-mu-shan Nature Preserve, near the ranger's cabin; 32³4'34.00" N, 113²4'23.67" E; 215 m a.s.1.; 9 Apr. 2015; Qiu Shuang and Liu Tian-yu leg.; hand net; NAU.

\section{Description}

\section{Male}

HEAD. Head brown, in anterior view with short dark line in centre of frons (Fig. 3A); frontogenal compact setal warts large, approximately $2 \times$ as long as wide, with dark line connecting ventral end of each setal wart and clypeus. Anterior tentorial pits located very close to clypeus. In dorsal view with dark median dorsal line (Fig. 3B). Median dorsal line branched and extending to bases of antennae, between vertexal mediantennal compact setal warts and vertexal lateroantennal compact setal warts, and present with curved horizontal branches posteriorly. Vertexal lateroantennal compact setal warts smaller than vertexal mediantennal compact setal warts. Occipital setal warts oval, smaller than oval postgenal setal warts. Maxillary palps lost in the dissection process.

WiNGS. Forewings each $7.7 \mathrm{~mm}(\mathrm{n}=1)$, dark brown; DC present, fork I slightly longer than fork II, $\mathrm{R}_{4+5}$ not fused with $\mathrm{R}_{3}, \mathrm{Cu}_{2}$ absent; row of setae located close to posterior margin of each forewing. Hind wing $\mathrm{C}$ with hump and row of setae in middle; $\mathrm{R}_{1}$ disappearing after crossvein Sc-r; DC absent (Fig. 3C).

Male genitalia. Tergum IX narrow in lateral view (Fig. 3D), fused with median dorsal process of segment $\mathrm{X}$ forming long thin process (Fig. 3E); sternite of segment IX truncate, with large anterior process in lateral view (Fig. 3D) and triangular concavity on posterior margin in ventral view (Fig. 3F). Lateral process of segment $\mathrm{X}$ with two pairs of short branches: apical branches round, with one short spine postero-ventrally; subapical branches forked into few acute ends in dorsal and lateral views (Fig. 3H). Superior appendages leaf-like in lateral view (Fig. 3D) and digitate in dorsal view (Fig. 3E), longer than dorsal process of Tergite IX. Coxopodites wider basally than apically in lateral and ventral views, with bases strongly sclerotized (Fig. 3D, F); harpagones about $1 / 3$ as long as coxopodites, each 

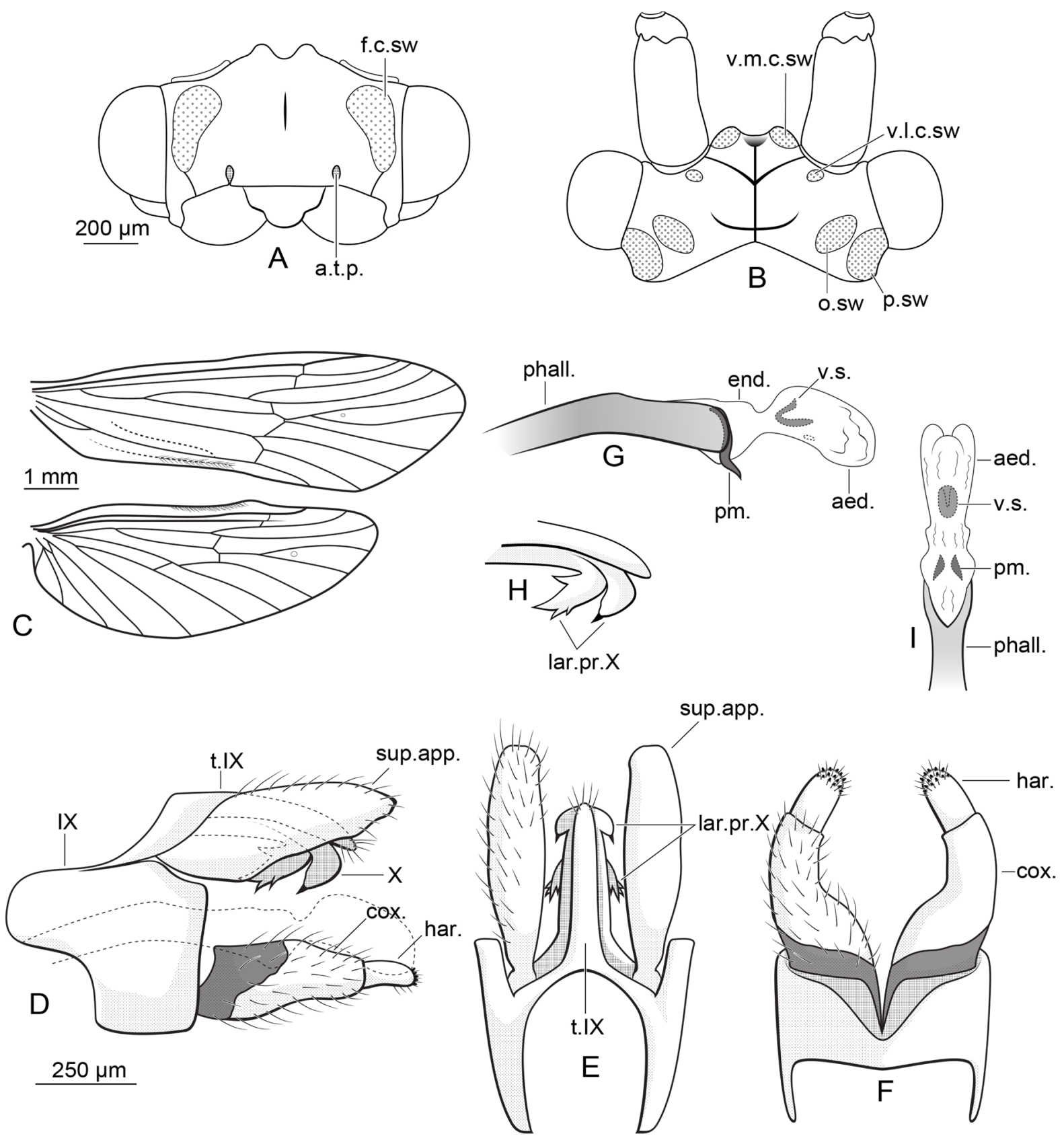

Fig. 3. Psilotreta brevispinosa sp. nov. A. Head, anterior view. B. Head, dorsal view. C. Wing veins. D. Male genitalia, left lateral view. E. Male genitalia, dorsal view. F. Male genitalia, ventral view. G. Phallus, left lateral view. H. Segment X, left lateral view. I. Phallus, ventral view, with basal half of phallotheca omitted. Scale bars: A-C $=200 \mu \mathrm{m} ; \mathrm{D}=1 \mathrm{~mm}$; $\mathrm{E}-\mathrm{K}=250 \mu \mathrm{m}$. 
with small spines and setae on apices (Fig. 3F). Phallotheca sclerotized, thin and long, slightly curved ventrally in lateral view (Fig. 3G), apex forked in ventral view (Fig. 3I); parameres present, slightly longer than height of phallotheca in lateral view (Fig. 3G), with apices curved posteriorly; endotheca and aedeagus membranes, ventral sclerite of aedeagus strongly curved in lateral view (Fig. 3G) and oval in ventral view (Fig. 3I).

\section{Distribution}

This species has been found only in Henan Province, China. The wider distribution is unknown.

\section{Discussion}

According to Oláh \& Johanson (2010), the three discribed species found in the Dabie Mountains all belong to the Psilotreta japonica species group, as their harpagones are located on the apices of the coxopodites with numerous small spines at the end, and they all have one pair of parameres.

According to Yuan \& Yang (2013), Psilotreta daidalos and P. furcata sp. nov. belong to the P. chinensis species group, as the harpagones are not forked, segments 1-2 of each maxillary palp are approximately the same length, and the intermediate appendages are present. Psilotreta brevispinosa sp. nov. cannot be assigned to an existing species group. The fusing of segments IX-X and the absence of intermediate appendages show some similarities with Psilotreta apiculata Yuan \& Yang, 2013 or P. monacantha Yuan \& Yang, 2013; however, the phallus of $P$. apiculata lacks parameres and the forewings of $P$. monacantha lack DC, while $P$. brevispinosa has both parameres and DC present. These are significant differences, so the three aforementioned species cannot be considered to be closely related. More characters are needed to analyse the position of $P$. brevispinosa sp. nov.

\section{Acknowledgements}

We appreciate Prof. Yang Lianfang and Prof. Sun Changhai of Nanjing Agriculture University, P.R.China, for their enlightening help with the identifications of Trichoptera, and for preserving the types. We also thank Dr John C. Morse of Clemson University, USA, for his instructions on studying trichopterology, and his help on collecting references. We would also like to thank Liu Tianyu for his help with field work. We are grateful to the comments of the reviewers and to the editor that helped us to get this manuscript published.

\section{References}

Banks N. 1899. Descriptions of new North American neuropteroid insects. Transactions of the American Entomological Society 25: 199-218. Available from http://www.trichopteralit.umn.edu/PDFs/BANKS_1899_48.pdf

Malicky H. 2000. Einige neue Köcherfliegen aus Sabah, Nepal, Indien und China (Trichoptera: Rhyacophilidae, Hydrobiosidae, Philopotamidae, Polycentropodidae, Ecnomidae, Psychomyiidae, Hydropsychidae, Brachycentridae, Odontoceridae, Molannidae). Braueria 27: 32-39. Available from https://www.zobodat.at/pdf/BRA_27_0032-0039.pdf

Morse J. C. 2018. Trichoptera World Checklist. Available from http://entweb.clemson.edu/database/trichopt/index.htm [accessed 25 Mar. 2019].

Nielsen A. 1957. A comparative study of the genital segments and their appendages in male Trichoptera. Biologiske Skrifter udgivet af Det Kongelige Danske Videnskabernes Selskab 8 (5): 1-159.

Oláh J. \& Johanson K.A. 2007. Trinominal terminology for cephalic setose warts in Trichoptera (Insecta). Braueria 34: 43-50. Available from https://www.zobodat.at/pdf/BRA_34_0043-0050.pdf 
Oláh J. \& Johanson K.A. 2010. Description of 33 new species of Calamoceratidae, Molannidae, Odontoceridae and Philorheithridae (Trichoptera), with detailed presentation of their cephalic setal warts and grooves. Zootaxa 2457: 1-128. https://doi.org/10.11646/zootaxa.2457.1

Parker C.R. \& Wiggins G.B. 1987. Revision of the caddisfly genus Psilotreta (Trichoptera: Odontoceridae). Royal Ontario Museum Life Sciences Contributions 144: 1-55.

https://doi.org/10.5962/bhl.title.52238

Yang L., Sun C. \& Morse J.C. 2016. An amended checklist of the caddisflies of China (Insecta, Trichoptera). Zoosymposia 10: 451-479. https://doi.org/10.11646/zoosymposia.10.1.42

Yuan H. \& Yang L. 2008. Descriptions of five new species of the genus Psilotreta (Trichoptera, Odontoceridae) from China. Acta Zootaxonomica Sinica 33(3): 608-614.

https://doi.org/10.3969/j.issn.1000-0739.2008.03.035

Yuan H. \& Yang L. 2010. Descriptions of four new species of Psilotreta (Trichoptera, Odontoceridae) from China. Acta Zootaxonomica Sinica 35 (3): 613-618.

Yuan H. \& Yang L. 2011. Descriptions of two new species and a new record of Psilotreta (Trichoptera, Odontoceridae) from China. Acta Zootaxonomica Sinica 36 (4): 956-960.

Yuan H. \& Yang L. 2013. Descriptions of three new species of the genus Psilotreta (Trichoptera, Odontoceridae) from China. Acta Zootaxonomica Sinica 38 (1): 114-118.

Yuan H., Yang L. \& Sun C. 2008. Descriptions of three new species of Psilotreta (Trichoptera, Odontoceridae) from China. Acta Zootaxonomica Sinica 33 (2): 380-384.

https://doi.org/10.3969/j.issn.1000-0739.2008.02.031

Manuscript received: 1 April 2019

Manuscript accepted: 4 November 2019

Published on: 6 February 2020

Topic editor: Gavin Broad

Desk editor: Jeroen Venderickx

Printed versions of all papers are also deposited in the libraries of the institutes that are members of the EJT consortium: Muséum national d'histoire naturelle, Paris, France; Meise Botanic Garden, Belgium; Royal Museum for Central Africa, Tervuren, Belgium; Royal Belgian Institute of Natural Sciences, Brussels, Belgium; Natural History Museum of Denmark, Copenhagen, Denmark; Naturalis Biodiversity Center, Leiden, the Netherlands; Museo Nacional de Ciencias Naturales-CSIC, Madrid, Spain; Real Jardín Botánico de Madrid CSIC, Spain; Zoological Research Museum Alexander Koenig, Bonn, Germany; National Museum, Prague, Czech Republic. 